\title{
Express Assessment of the Students' Adaptive Abilities and Revealing of the Risk Group
}

\author{
Mishchenko Natalia Vladimirovna ${ }^{1}$, Trifonova Tatiana Anatolievna ${ }^{2} \&$ Klimov Ivan Alekseevich ${ }^{1}$ \\ ${ }^{1}$ Vladimir state university named after Alexander and Nikolay Stoletovs, Vladimir, Russia \\ ${ }^{2}$ Lomonosov Moscow State University, GSP-1, Leninskie Gory, Moscow, Russia \\ Correspondence: Mishchenko Natalia Vladimirovna, Vladimir state university named after Alexander and \\ Nikolay Stoletovs, 87, Gorky str, Vladimir, 600000, Russia.
}

Received: October 10, $2014 \quad$ Accepted: October 20, $2014 \quad$ Online Published: December 2, 2014
doi:10.5539/ass.v11n1p313

\begin{abstract}
The educational process in the higher educational establishments should contribute to the formation of the independent, initiative, creative and healthy personality. However, some students have different functional disturbances during the education, their health can worsen. The aim of this investigation is the express assessment of the regulatory body systems conditions of the students of different year in Vladimir State University and revealing of the risk group of students, who are exposed to the adaptive processes disorders, basing on the heart rate variability analysis. The students of different specializations at the age of 17 to 22 from Vladimir State University were examined. Total amount was 200 people, among which there were: 100 girls and 100 boys. Software and hardware complex "Zdorovie-express" was used; there were determined heart rate variability values, which were used to calculate the complex index of the regulatory body systems activity as well as to assess general cardiac output using the indices of the heart rate, pulse and cardiac muscle. The conducted investigations show high effectiveness of use of regulatory body systems activity index for the express assessment of the students' adaptive abilities and revealing risk groups. The acquired results speak for the fact that the load, suffered by the students in the process of education in the university, is a sufficient stressor and can result in the significant strain of the regulatory body systems for the most part of students (67\%) and 14\% of students are in the risk group which is characterised by the overstrain of the regulatory body systems and different stages of adaptation failure. Aggravation of the adaptation mechanism was noted by the 4th year of study. These results can be used for optimization of the educational process in the higher educational establishments as well as for the organization of the preventive works among students, correct organization of the sanitary measures.
\end{abstract}

Keywords: adaptation, heart rate variability, regulatory body systems activity index, students

\section{Introduction}

In modern higher educational establishments one can observe continuous intensification of the educational process, complication of its content, implementation of new informational methods of training, which increase the strain on students. The educational process should contribute to the formation of the independent, initiative, creative and healthy personality. But some students have different functional disturbances during the education and their health can worsen (Ryumina et al., 2012; Davidenko et al., 2005; Gevorkyan \& others, 2003; Yusoff, 2010).

That's why the analysis of the young people adaptive abilities in the higher educational establishments and revealing risk groups of students having high probability of functional disturbances development is of urgent character (Stewart et al., 1996; Агаджанян, 1994). Adaptive processes activate when the habitual conditions are changing and it becomes necessary to accommodate to the new situations. It is the thing that the students face starting from the 1st year of study, when their lifestyle and education system are changed. In the process of adaptation the students suffer difficulties, for example, accommodation to the new study schedule; the emotions connected with the leaving of the habitual school group of people; apprehension of the career choice etc (Mazumdar, 2012; Ansari, 2011; Blom, 2009 ). In the previous investigations it was noted that the adaptive processes are more difficult for the students who live far away from their parents, who moved home. Students' adaptation is a complex process which is affected by a lot of different factors. It includes the changes of the level 
of separate systems functioning and the strain of the regulatory systems. In case of failures in the work of these systems there appear functional and organic changes in the human body. Decrease of the students' adaptive potential is considered as a risk factor of diseases development since even an insignificant aggravation of adaptive abilities can lead to the serious health problems (Gavrilova, 2004; Altynova, 2009).

The most sensitive indicator of adaptive processes is the cardiovascular system, Heart rate and force which are controlled by the sympathetic and parasympathetic divisions of the autonomic nervous system, immediately respond to any changes of the environment and are widely used for the characterisation of the adaptive reserves, regulatory mechanisms and stress level (Ihlen, 2009; Ситдиков, 2001.) Nowadays the most convenient index of the interaction effectiveness of the cardiovascular system and other body systems is the heart rate variability (Бабунц, 2002). The method of heart rate variability analysis becomes popular and is widely used in the functional diagnostics due to the fact that it is operational and non-invasive. This analysis allows to give a general assessment of the human state, since it characterises vital indices of the body physiological functions control (functional reserves and autonomic balance) (Baevskiy, 2001; Bailôna et al., 2010; Malik, 1998).

In the course of some years the authors assess physical state and adaptive abilities of students, reveal students with the decreased adaptive potential as well as study the influence of different factors on the human health (Ryumina et al., 2012; Trifonova et al., 2012)

The aim of this investigation is the express assessment of the regulatory body systems conditions of the students of different year in Vladimir State University and revealing of the risk group of students, who are exposed to the adaptive processes disorders, basing on the heart rate variability analysis.

\section{Objects and Methods of Investigation}

The students of different specializations at the age of 17 to 22, studying under the Vladimir State University were examined. Total amount was 200 people, among which: 100 girls and 100 boys. The students, who took part in the experiment, were not subject to regular medical check-up concerning any chronic conditions. The examination was conducted during the education process in 2013. For this purpose the hardware-software complex "Zdorovye-express" was used. This complex is designed for the screening-assessment of the psycho-physiological and somatic health level, body reserves and physical development parameters. Basing on the acquired data the complex displays individual recommendations for the state correction and healthy lifestyle choice (www.mks.ru/dev/functionaltest/healthexpress). Two modules of the hardware-software complex "Zdorovye-express" - "Cardiovisor" and "Heart rate variability" - were used. The output data for these modules was the record of the ECG extremity lead signals which lasted for 3 minutes. Cardiovisor analyses micro-alterations of the ECG line signal. As the result there appears the map of the dispersive heart changes in the form of the heart portrait. A range of other characteristics is also calculated. Among these we used such as "Cardiac muscle", "Rate" and "Pulse" Indices. They characterise the total value of the dispersive abnormalities and are changing in the range of $0 \%-100 \%$. The more is the index value, the more is abnormality.

"Heart rate variability" module records the duration of R-R intervals of the electrocardiogram (also called R-R intervals), builds dynamic raw of R-R intervals (cardio interval graphic) and performs mathematical analysis of the acquired data, with the help of which it assesses the human state and his/her adaptive reserves.

Table 1. Algorithm of the index of activity of the regulatory systems (IARS)

\begin{tabular}{|c|c|}
\hline Regulatory system characteristics & Criteria for their assessment \\
\hline A. Total effect of regulation & rNN -average value of the RR-intervals, $s$ \\
\hline B. Heart automatism & $\begin{array}{l}\text { SDNN -standard abnormality of all } R R \text { - intervals } \\
\text { dX- range, } s \\
\text { CV - variation coefficient, \% }\end{array}$ \\
\hline $\begin{array}{l}\text { C. Autonomic homeostasis (balance } \\
\text { of the sympathetic and } \\
\text { parasympathetic influences) }\end{array}$ & $\begin{array}{l}\text { dX- range, } \mathrm{s} \\
\text { AMo-mode amplitude, } \% \\
\text { IN - regulatory systems strain index }\end{array}$ \\
\hline D Regulation stableness & $\mathrm{CV}$ - variation coefficient, $\%$ \\
\hline E. Subcortical nerve centres activity & $\begin{array}{l}\mathrm{VLF} / \mathrm{TF} ; \mathrm{LF} / \mathrm{TF} ; \mathrm{HF} / \mathrm{TF} \text {, where VLF- is a power of high-frequency conten } \\
\text { of the spectrum, } \mathrm{ms}^{2} ; \mathrm{LF} \text { is a power in the low frequency range, } \mathrm{ms}^{2} ; \mathrm{HF} \text { is } \\
\text { power of the high-frequency part of the spectrum, } \mathrm{ms}^{2} ; \mathrm{TF}=\mathrm{VLF}+\mathrm{LF}+\mathrm{HF}\end{array}$ \\
\hline
\end{tabular}


In order to perform the complex analysis of the heart rate variability parameters we used the index of activity of the regulatory systems (IARS) calculation method, suggested by Baevskiy R. M. (www.zdex.ru/support/manuals; Baevskiy, 2000; Баевский, 1997). This method is based on the fact that different states and functional characteristics of the regulatory systems can be assessed by one or several heart rate variability parameters. IARS was calculated for each student with the help of the hardware-software complex using the special algorithm which takes into account statistic indices, histogram values and R-R intervals spectrum analysis; each criterion is assessed in points, the sum for the module is calculated as follows:

IARS $=|A|+|B|+|C|+|D|+|E|$

The algorithm of the IARS components and criteria characteristics calculation is presented in Table 1.

IARS takes values from 1 to 10 and allows to difirentiate various stages of regultory systems strain (Table 2).

Table 2. Interpretation of the index of activity of the regulatory systems (IARS)

\begin{tabular}{ccc}
\hline IARS meaning & Regulatory systems strain level & Functional status \\
\hline 1 & Optimal level & Normal \\
2 & Normal level & \\
3 & Moderate functional strain & \\
4 & Obvious functional strain & Donozological state \\
5 & Full-blown functional strain & \\
6 & Regulatory mechanisms overstrain & Premorbid states \\
7 & Full-blown overstrain & \\
8 & Regulatory systems deterioration & Adaptation failure \\
9 & Full-blown deterioration & \\
10 & Regulatory mechanisms failure & \\
\hline
\end{tabular}

This classification of functional states characterizes four health levels, four levels pf adaptive abilities of the body. An important thing here is that the uncertain notion of in-between states acquires some sense on the basis of concepts of adaptation and homeostasis. Within the framework of this simplified pattern the differentiated 10-points scale of functional states ("states ladder") was created. This scale allows assessing and forecasting functional states of the body, which are in between the norm and the pathology, in terms of regulatory systems strain degree.

\section{Results}

For the preliminary assessment of the general functional state of the heart we used "Pulse", "Cardiac muscle" and "Rate" indices, acquired with the help of the Cardiovisor module (Table 3). Average indices of cardiac muscle $(15.95 \pm 4.07$, normal value is less than $15 \%)$, pulse $(85.58 \pm 11.12$, normal value is $60-80$ beats/minute) and rate $(26.83 \pm 16.09$, normal value is less than $15 \%)$ are a little bit higher for all the selection and are noted by the significant data scatter. The results mean that on an average the students have normal functional characteristics of the heart, but their regulatory mechanisms are activated. The examined group of students is very inhomogeneous. That's why we performed the analysis of percentage ratio of students with different indices.

Functional state according to the "Cardiac muscle" index is normal for the most art of the students. Only 7\% of students have abnormalities which need dynamics control and, perhaps, additional examination in case of repeating abnormalities. The students of different years of study have no significant differences.

The "Rate" index is one of the markers for adaptive abilities of the body. Index value of more than $80 \%$ which could speak of the serious disturbances and obvious stress, was not found among the students. The most part of students (93\%) have the "Rate" index in the state of physiological norm, 7\% have in-between state. The students of different years of study have no significant differences. It is necessary to point out that the 2 nd year students more frequently have in-between states comparing to the other students.

Pulse indicator is dynamic. We cannot make any general conclusion according to the results of one or two measurements, but we can speak of the state of a human in the given time. During the examination 54\% of students have normal pulse, $22 \%$ have moderate tachycardia and $22 \%$ have obvious tachycardia. 
Table 3. Percentage ratio of students with different values of indices of rate, cardiac muscle and index of activity of the regulatory systems (IARS)

\begin{tabular}{|c|c|c|c|c|c|c|c|c|c|c|}
\hline \multirow{2}{*}{ Indicators } & \multicolumn{2}{|c|}{ 1st year } & \multicolumn{2}{|c|}{ 2nd year } & \multicolumn{2}{|c|}{ 3rd year } & \multicolumn{2}{|c|}{ 4th year } & \multicolumn{2}{|c|}{ total } \\
\hline & boys & girls & boys & girls & boys & girls & boys & girls & boys & girls \\
\hline \multicolumn{11}{|l|}{ Rate index, \% } \\
\hline No significant abnormalities (less than 15\%) & 25 & 19 & 9 & 23 & 39 & 17 & 25 & 19 & 24 & 20 \\
\hline Slight abnormalities (15-50\%) & 72 & 78 & 86 & 60 & 56 & 75 & 64 & 81 & 70 & 73 \\
\hline In-between state $(50-80 \%)$ & 3 & 3 & 5 & 17 & 5 & 8 & 11 & 0 & 6 & 7 \\
\hline Obvious abnormalities (more than $80 \%$ ) & 0 & 0 & 0 & 0 & 0 & 0 & 0 & 0 & 0 & 0 \\
\hline \multicolumn{11}{|l|}{ Cardiac muscle idex, \% } \\
\hline No significant abnormalities (less than 15\%) & 41 & 25 & 18 & 27 & 33 & 33 & 25 & 23 & 30 & 26 \\
\hline In-between state $(15-19 \%)$ & 53 & 63 & 77 & 70 & 61 & 59 & 61 & 77 & 62 & 68 \\
\hline Slight probability of pathology development $(20-22 \%)$ & 0 & 0 & 0 & 0 & 6 & 0 & 7 & 0 & 3 & 0 \\
\hline $\begin{array}{l}\text { Probable pathology development, dynamics control } \\
\text { needed }(22-27 \%)\end{array}$ & 3 & 6 & 5 & 3 & 0 & 8 & 0 & 0 & 2 & 4 \\
\hline $\begin{array}{c}\text { Pathological abnormalities, additional examination } \\
\text { needed (more than } 27 \% \text { ) }\end{array}$ & 3 & 6 & 0 & 0 & 0 & 0 & 7 & 0 & 3 & 2 \\
\hline \multicolumn{11}{|l|}{ IARS (index of activity of the regulatory systems), \% } \\
\hline Physiological norm & 28 & 31 & 0 & 23 & 6 & 25 & 14 & 15 & 14 & 24 \\
\hline Donozological state & 35 & 22 & 36 & 40 & 39 & 41 & 22 & 35 & 32 & 33 \\
\hline Premorbid state & 31 & 34 & 50 & 27 & 33 & 17 & 50 & 27 & 41 & 28 \\
\hline Adaptation failure & 6 & 13 & 14 & 10 & 22 & 17 & 14 & 23 & 13 & 15 \\
\hline
\end{tabular}

For the assessment of the students' adaptive status the characteristics of heart rate variability were determined (Table 4). Index of activity of the regulatory systems (IARS) was calculated. This index was the main one in the course of analysis of adaptive abilities and was the main criterion of students' assignment to the risk group. Average IARS value corresponds to the obvious functional strain of the regulatory systems both of boys (IARS $=5.67 \pm 1.70)$ and girls (IARS $=5.23 \pm 1.95)$.

Percentage ratio of students with different regulatory systems states is shown on Figure 1 and in Table 4.

Table 4. Average value of the students' heart rate variability indices

\begin{tabular}{|c|c|c|c|c|}
\hline \multirow{2}{*}{ Index } & \multicolumn{2}{|l|}{ boys } & \multicolumn{2}{|c|}{ girls } \\
\hline & Value & Normal & Value & Normal \\
\hline $\begin{array}{l}\text { SDNN -standard abnormality of all RR - } \\
\text { intervals, ms }\end{array}$ & $59.44 \pm 26.09$ & $28.5-71.6$ & $50.92 \pm 17.96$ & $30.5-71.9$ \\
\hline SI, stress index & $118.30 \pm 131.37$ & $32-283$ & $128.67 \pm 79.21$ & $37-216$ \\
\hline IC, centralization index & $4.10 \pm 2.84$ & $1.05-5.04$ & $3.82 \pm 4.63$ & $0.99-2.52$ \\
\hline $\begin{array}{l}\text { RMSSD, square root of the average sum of } \\
\text { squares of differences between the } \\
\text { adjecent RR -intervals, ms }\end{array}$ & $41.25 \pm 22.86$ & & $38.74 \pm 20.23$ & \\
\hline $\begin{array}{c}\text { VLF, power in the very low frequency } \\
\text { range, } \%\end{array}$ & $20.63 \pm 12.17$ & $7.6-23.8$ & $19.21 \pm 11.36$ & $8.4-24$ \\
\hline $\begin{array}{c}\text { HF, power of the high-frequency part of } \\
\text { the spectrum } \%\end{array}$ & $25.54 \pm 12.90$ & & $31.59 \pm 17.29$ & \\
\hline $\mathrm{LF}$, power in the low frequency range, $\%$ & $54.03 \pm 14.61$ & $36.8-66.8$ & $49.19 \pm 15.21$ & $30.4-57.1$ \\
\hline $\mathrm{TP}$, spectrum power, $\mathrm{ms}^{2}$ & $3576.25 \pm 3533.89$ & & $2452.86 \pm 1996.13$ & \\
\hline $\mathrm{LF} / \mathrm{HF}$ & $2.94 \pm 2.02$ & & $2.68 \pm 3.05$ & \\
\hline TPVLF, spectrum power, $\mathrm{ms}^{2}$ & $580.66 \pm 686.85$ & & $360.38 \pm 359.57$ & \\
\hline TPLF, spectrum power, $\mathrm{ms}^{2}$ & $1493.45 \pm 1156.69$ & & $922.00 \pm 734.45$ & \\
\hline AMo, mode amplitude, $\%$ & $39.00 \pm 14.10$ & $20.4-58.4$ & $41.47 \pm 11.86$ & $23.6-44.1$ \\
\hline
\end{tabular}




\section{Results Discussion}

The acquired results correspond to the many of literature data about the fact that the heart rate variability parameters as well as the results of their mathematical processing are reliable and informative indices for the assessment of the regulatory systems state, adaptive abilities and susceptibility to the stress influences (Antonio Luque-Casado, 2013; Luft, 2009). The investigations in this sphere have been conducting for a long time using different, constantly improving methods (Lombardi \& Mortara, 1998; Ravenswaaij et al., 1993; Berntson et al., 1997, Berger et al., 1986).

Almost all the measurements of the heart rate variability indices correspond to the normal data according to the average norm (Table 3). It was noted while performing similar investigations by the other authors (Lutsenko \& Gabelkova, 2013; Chuyan et al., 2008).

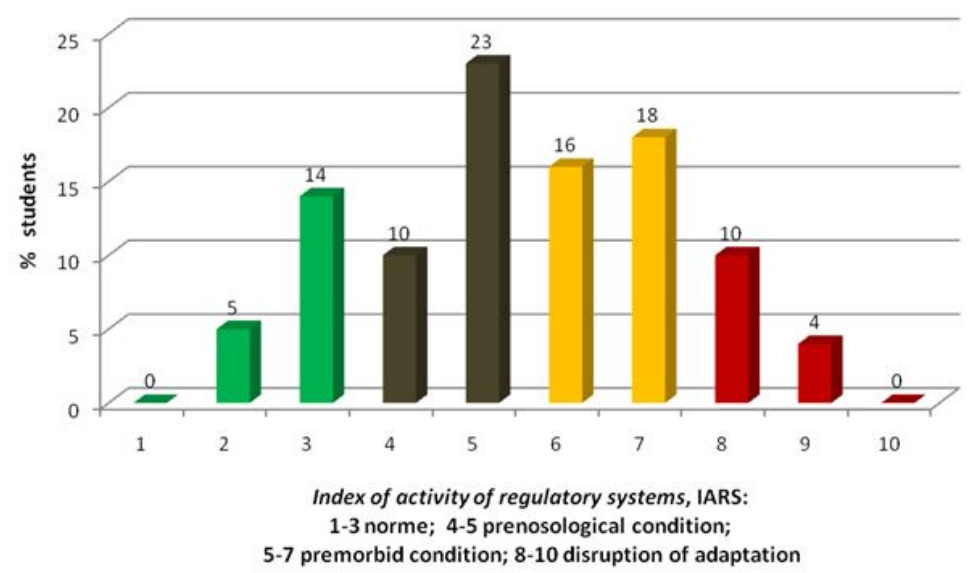

Figure 1. Students' body regulatory systems activity index (the whole selection)

The calculated averaged complex index of IARS shows the functional strain of regulatory systems, but it doesn't show the number of students with normal indices and students having abnormalities of different degree. That's why we performed the analysis of percentage ratio of the investigated students with different characteristics.

The analysis of the percentage ratio of students having different character of adaptive processes development according to the IARS showed the absence of the investigated people with both highly unfavourable and optimal states. There are no students with the IARS 10 index (Figure 1), i.e. in the state of the maximum stress and complete disturbance of adaptive processes. However, $14 \%$ have significant deterioration of adaptive resources (IARS $=8-9$ ). Also there are no students with the most optimal state of the regulatory systems; there are few students, both among boys and girls, with the index 2, which corresponds to the peaceful state.

Most of the students are on different levels of functional strain (IARS is from 4 up to 7). This state can be considered as a normal adaptive response of the healthy orgaism to the stress influences, which in this case are the education conditions; it should not lead to the disease development in the future. The ranges of investigations show that the second phase of stress not necessarily transfers to the deterioration phase and develops into the adaptation failure. The organism in the state of regulatory systems strain is characterised by the high resistance to the diseases on the account of sympathetic and sympathoadrenal activations. Toprevent stress from changing into distress it is important to orient students of this group to the healthy behaviour and cognitive activity (Lutsenko \& Gabelkova, 2012; Michie, 2012).

The 10-point scale is reasonable to be used in individual analysis of the students' state. For the sake of convenience of the mass data the indices can be combined in 4 classes according to the scheme, offered by its creators (Table 2). We used this scheme in the comparative characteristic of the students of different years of study (Figure 2).

We did not notice any significant difference among the students of different years of study. Regulatory systems activity is far better during the 1st year of study. $30 \%$ of students are in the state of physiological norm. Their state aggravates by the $3 \mathrm{rd}$ and 4 th year of study. Only $13 \%$ of students have physiological norm, $20 \%$ have adaptive processes failures. 


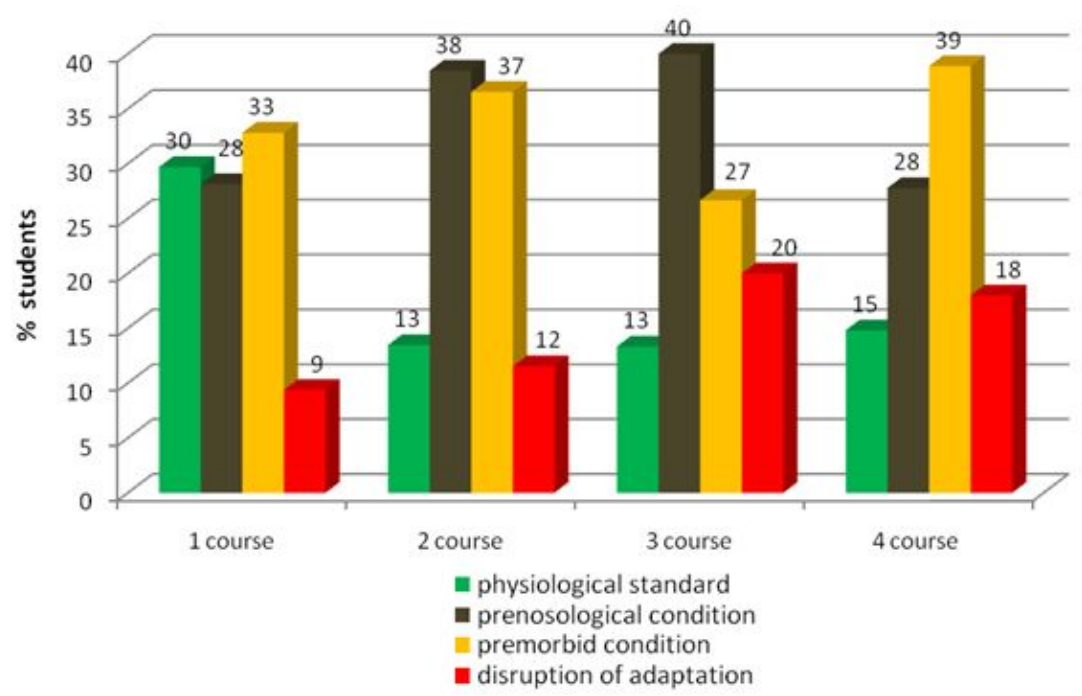

Figure 2. Adaptive mechanisms state of students of different years of study

The investigators points out the necessity of students' examination aimed at revealing regulatory systems disorders starting from the 1 st year of study. The examination is aimed at preventing regulatory systems overstrain and optimization of educational process (Poborskiy, 2007). Taking this fact into account we used the index of activity of the regulatory systems for the revealing of the risk groups of students. To this group we referred students who were healthy at the moment of examination but had high probability of diseases development due to the probable regulatory systems deterioration. 14\% of students (total amount of students were 28: 13 boys and 15 girls) were in the risk group; their IARS index was more than 8 and they had a slight probability of adaptive failure. As an example of abnormalities which were observed for the students of this group, we can take a student with the IARS index $=9$; he had serious abnormalities according to 4 of 5 characteristics, which include heart automatism, autonomic homeostasis, regulation stableness, subcortical centres activity.

Persons of the risk group are recommended to have additional examination, to correct their lifestyle and to have medical supervision.

\section{Report}

Thus, the conducted investigations show high effectiveness of use of regulatory body systems activity index for the express assessment of the students' adaptive abilities and revealing risk groups. The acquired results speak for the fact that the load, suffered by the students in the process of education in the university, is a sufficient stressor and can result in the significant strain of the regulatory body systems for the most part of students (67\%) and $14 \%$ of students are in the risk group which is characterised by the overstrain of the regulatory body systems and different stages of adaptation failure. Insignificant aggravation of the adaptation mechanism was noted by the 4 th year of study.

These results can be used for optimization of the educational process in the higher educational establishments as well as for the organization of the preventive works among students, correct organization of the sanitary measures. These results have certain restrictions in usage since no differentiation of students according to the academic progress and lifestyle was made. The investigations are to be continued in order to find certain reasons which cause regulatory systems overstrain as well as revealing different adaptive responses amog students of different specialities (humane and technical).

\section{Acknowledgements}

The scientific publication was prepared within the framework of the governmental task of Vladimir State University No. 2014/13 for the performance of the governmental works in the sphere of scientific activity.

\section{References}

Altynova, N. V., Panikhina, A. V., Anisimov, N. I., \& Shukanov, A. A. (2009). Physiological status of the 1st year students under the conditions of education in the higher educational establishment. In the world of scientific discoveries, 3(2), 103. 
Baevskiy, R. M., \& Ivanov G. G., (2000). Heart rate variability: Theoretical aspects and possibilities of clinical use. Moscow: Medicine.

Baevskiy, R. M., (2001). Heart rate variability analysis with different electrocardiographic systems (methodological recommendations). Arrhythmology messenger, 24, 65-87.

Gavrilova, I. N., \& Gorbunov, N. P., (2004). Peculiarities of physiological adaptation of female students who belong to different ethnic groups. Russian physiological journal under the name of I. M. Sechenov, 90(8), 184.

Gevorkyan, E. S., Dayan, A. V., Adamyan, Ts. I., Grigoryan, S. S., \& Minasyan, S. M. (2003). Examination stress influence on the psycho-physiological indices and heart rate variability among female students. Higher nervous activity journal, 53(1), 46-50.

Davidenko, D. N., Shchedrin, Yu. N., \& Shchyogolev, V. A. (2005). Health and lifestyle of students. St. Petersburg, St. Petersburg State University ITMO.

Lutsenko, E. L., \& Gabelkova, O. E. (2013). Connection of the heart rate variability and psychological peculiarities which determine healthy behavior. Psychophysiology messenger, 1, 24-30.

Poborskiy, A. N. (2007). Peculiarities of heart rate regulation for the students with different levels of anxiety before the start of education under the unfavourable conditions of the Middle Ob region. SO RAS Bulletin, 3(125), 191-196

Ryumina, E. A., Mishchenko, N. V., \&Trifonova, T. A. (2012, May). Adaptive capabilities assessment of the 2nd year students of the higher educational establishment. ZNiSO, 5(230), 40-42.

Chuyan, E. N., Biryukova, E. A., \& Ravaeva, M. Yu. (2008). Complex approach to the assessment of the students' organism functional state. Scientific notes of the Taurida National V.I. Vernadsky University. "Biology, Chemistry" series, 21(60), 123-139.

Berger, R. D., Akselrod, S., Gordon, D., \& Cohen, R. J. (1986). An efficient algorithm for spectral analysis of heart rate variability. IEEE Trans Biomed Eng., 33, 900-904. http://dx.doi.org/10.1109/TBME.1986.325789

Berntson, G. G., Bigger, J. T., \& Eckberg, D. L. (1997). Heart rate variability: Origins, methods and interpretative caveats. Psychophysiology, 34, 623-648. http://dx.doi.org/10.1111/j.1469-8986.1997.tb021 40.x

Lombardi, F., \& Mortara, A. (1998). Heart rate variability and cardiac failure. Heart, 80, 214-231. http://dx.doi.org/10.1136/hrt.80.3.213

Malliani, A. (1995). Association of heart rate variability components with physiological regulatory mechanisms. In M. Camm (Ed.), Heart rate variability. Futura Pub Comp.

Malik, M. (1998). Heart rate variability. Curr Opin Cardiol, 13, 36-44. http://dx.doi.org/10.1097/00001573199801000-00006

Michie, S., \& Johnston, M. (2012). Theories and techniques of behaviour change: Developing a cumulative science of behaviour change. Health Psychology Review, 6(1), 1-6. http://dx.doi.org/10.1080/17437199. 2012.654964

Raquel, B. (2010). Analysis of heart rate variability during exercise stress testing using respiratory information. Biomedical Signal Processing and Control, 5, 299-310. http://dx.doi.org/10.1016/j.bspc.2010.05.005

Stewart, S. M., Betson, C., \& Marshall, J. (1996). Stress and vuneravitily in medical students. Med. Education, 29, 119-126. http://dx.doi.org/10.1111/j.1365-2923.1995.tb02814.x

Trifonova, T., Krasnoshchekov, A., \& Mishchenko, N. (2012). Population 'habitation comfort' indicators for areal comparison in Central Russia, Human geographies. Journal of Studies and Research in Human Geography, 6(2), 55-61. http://dx.doi.org/10.5719/hgeo.2012.62.55

Van Ravenswaaij, C. M. A., Kollee, L. A., \& Hopman, J. C. V. (1993). Heart rate variability I I. Ann. Int. Med. V., $118,436$.

Hardware-software complex "Zdorovye-express". Retrieved September 2, 2013, from http://www.mks.ru/dev/ functionaltest/healthexpress

"Zdorovye-express" User's manual. "Medical Computer Systems" LLC. Retrieved September 2, 2013, from http://www.zdex.ru/support/manuals. 
Ihlen, E. A. (2009). A comparison of two Hilbert spectral analyses of heart rate variability. Medical \& Biological Engineering \& Computing, 47(10), 1035-1044. http://dx.doi.org/10.1007/s11517-009-0500-x

Henje Blom, E. (2009). Heart rate variability is related to self-reported physical activity in a healthy adolescent population. European Journal of Applied Physiology, 106(6), 877-883. http://dx.doi.org/10.1007/s00421009-1089-3

Luft, C. D., Takase, E., \& Darby, D. (2009). Heart rate variability and cognitive function: Effects of physical effort. Biological Pshysiology, 82(2), 164-168.

Antonio, L. -C., Zabala, M., Morales, E., Manuel, M. -M., \& Sanabria, D. (2013). Cognitive Performance and Heart Rate Variability: The Influence of Fitness Level. PLOS ONE, 8(2), e56935, http://dx.doi.org/10.1371/journal.pone.0056935

El Ansari, W., Stock, C., John, J., Deeny, P., Phillips, C., Snelgrove, S., Adetunji, H., Hu, X., Parke, S., Stoate, M., \& Mabhala, A. (2011). Health promoting behaviours and lifestyle characteristics of students at seven universities in the UK. Cent Eur J Public Health, 19(4), 197-204.

Yusoff, M. S. B., \& Rahim, A. F. A. (2010). Impact of medical student well-being workshop on the medical students' stress level: a preliminary study asean. Journal of Psychiatry, 11(1), 56-63.

Mazumdar, H., Gogoi, D., Buragohain, L., \& Haloi, N. (2012). A Comparative study on stress and its contributing factors among the Graduate and Post-graduate students. Advances in Applied Science Research, 3(1), 399-406.

\section{Copyrights}

Copyright for this article is retained by the author(s), with first publication rights granted to the journal.

This is an open-access article distributed under the terms and conditions of the Creative Commons Attribution license (http://creativecommons.org/licenses/by/3.0/). 